\title{
SOB FOUCAULT: A GOVERNAMENTALIDADE NEOLIBERAL ATRAVÉS DA EDUCAÇÃO CORPORATIVA
}

\section{UNDER FOUCAULT: NEOLIBERAL GOVERNMENT THROUGH CORPORATE EDUCATION}

Edinalva de Cassia Piovesan ${ }^{1}$

Márcia A. Amador ${ }^{2}$

\begin{abstract}
RESUMO: Este estudo tem como objetivo discutir a relação de poder-saber da educação corporativa que transita na governamentalidade do discurso neoliberal e, atua subjetivamente nos sujeitos profissionais das empresas. A complexidade do mercado faz das empresas, atuarem de maneira competitiva em prol de seus objetivos corporativos e mercadológicos. Diante do mercado globalizado, as organizações se veem num contexto em que qualificar seus colaboradores se torna fundamental para poder interagir e propiciar melhor desempenho corporativo, garantindo sua permanência no mercado, através do capital intelectual. A educação corporativa irá permitir que a empresa qualifique seus colaboradores, para que estes desempenhem seu papel profissional de maneira ágil e rápida frente aos desafios do mercado. Os colaboradores mobilizados pela dinâmica deste mercado e com a necessidade de manter-se empregado buscam adquirir novas competências que os torne multidisciplinar, permitindo ampliar suas responsabilidades na empresa. A qualificação pode se manifestar de diferentes formas, sendo: treinamentos, cursos, congressos etc. O referencial teórico e a análise buscou respaldar nos conceitos foucaultianos, na $2^{\mathrm{a}}$ fase, o domínio de saber-poder. A metodologia aplicada nesta pesquisa é a qualitativa, a qual buscou interpretar os excertos de entrevistas realizadas com colaboradores de uma empresa. Os resultados da análise demonstram que neste mercado neoliberal, a educação corporativa atua como um discurso que influência na relação do sujeito para com a empresa, propiciando interesses mútuos, seja para o sujeito com capital humano, quanto para a empresa com o capital intelectual.
\end{abstract}

Palavras-chave: Capital Humano. Educação. Governamentalidade Neoliberalismo.

\begin{abstract}
This study aims to discuss the power-knowledge relationship of corporate education that transits in the governance of neoliberal discourse, and acts subjectively on the professional subjects of companies. The complexity of the market makes companies act in a competitive way in favor of their corporate and market objectives. Facing the globalized market, organizations see themselves in a context where qualifying their employees becomes fundamental to interact and provide better corporate performance, ensuring their permanence in the market, through intellectual capital. Corporate education will allow the company to qualify its employees, so that they can play their professional role in an agile and fast way in the face of market challenges. The employees mobilized by the dynamics of this market and with the need to remain employed seek to acquire new skills that make them multidisciplinary, allowing them to expand their responsibilities in the company. The qualification can manifest itself in different ways, being: trainings, courses, congresses, etc. The theoretical reference and the analysis sought to support the Foucaultian Conceptions, in the 2nd phase, the domain of being-power. The methodology applied in this research is the qualitative one, which sought to interpret the excerpts of interviews conducted with employees of a company. The results of the analysis demonstrate that in this neoliberal market, the corporative education acts as a discourse that influences on the relation of the subject to the
\end{abstract}

${ }^{1}$ Mestranda em Educação pela Universidade São Francisco. E-mail: edinalva_piovesan@hotmail.com

${ }^{2}$ Professora do Programa de Pós-Graduação Stricto Sensu em Educação da Universidade São Francisco. E-mail: marciaaam@uol.com.br

Cadernos Cajuína, V. 6, N. 1, 2021, p. 23-35.

ISSN: 2448-0916 
company, propitiating mutual interests, either to the subject with human capital, as to the company with intellectual capital.

Keywords: Human Capital. Education. Governance. Neoliberalism.

\section{INTRODUÇÃO}

Vivemos em um mundo cercado de organizações, em que são responsáveis por produzir bens e serviços e oferecê-los à sociedade inserida mundialmente. As empresas possuem objetivo, a qual projetam suas ações para alcançá-los. Neste mercado, denominado como globalizado (sem fronteiras) é por sua vez dinâmico, exigindo das empresas rapidez, velocidade para lidar com as constantes mudanças. Isso permite que as relações estabelecidas entre organizações de diferentes países, possibilite a comercialização de produtos, serviços e informações. Este mercado global é composto por agentes como: políticas, econômicas, legais, tecnológicas, socioculturais, que interagem com forças e, que podem comprometer a atuação da empresa.

Diante de tal complexidade, as organizações se veem num contexto em que qualificar seus colaboradores (empregados) é fundamental para poder interagir e atender aos agentes, alcançar seus objetivos previamente planejados e também propiciar o melhor desempenho no mercado globalizado. A qualificação irá oferecer condições do empregado em enfrentar situações que irão exigir a aplicação de seus conhecimentos com rapidez e segurança. Sob de diferentes formas a qualificação se manifesta no ambiente corporativo através de treinamentos, cursos, workshops etc, que podem ser oferecidos no próprio recinto da empresa ou em ambientes externos. O objetivo geral deste estudo é contribuir para discutir a educação corporativa e as relações de poder-saber que atravessam os sujeitos no momento da governamentalidade neoliberal. Como objetivo específico desta pesquisa é levantar como a educação corporativa atua subjetivamente e se faz presente nos dizeres dos sujeitos de pesquisa. Os colaboradores mobilizados pela dinâmica do mercado e com a necessidade de manter-se empregado buscam adquirir novas competências que os torne multidisciplinar, permitindo ampliar suas tarefas (responsabilidade) na empresa.

A justificativa do tema é diante do referencial teórico utilizado para construir este estudo a partir dos estudos foucaultianos, na $2^{\mathrm{a}}$ fase, o domínio de ser-poder. Para Foucault (2015), o poder não é um objeto, mas uma relação do sujeito com a sociedade, visando um objetivo econômico e político. Desta forma, a eficácia destes objetivos para com a relação da empresa e funcionários, está nas estratégias aplicadas pelas empresas para sua manutenção no mercado, que neste caso, através da qualificação dos funcionários.

A metodologia de pesquisa utilizada para o estudo é a partir dos preceitos foucaultianos, que ao analisar o discurso, leva em consideração o contexto sócio histórico a que ele se vincula, no caso, a racionalidade do Governamento Neoliberal.

Esta pesquisa é qualitativa, pois possui algumas peculiaridades, como "é descritiva; os pesquisadores qualitativos estão preocupados com o processo e não simplesmente com os resultados e 
produtos [...] e tendem a analisar seus dados indutivamente" (TRIVIÑOS, 1987, p.128).

Esta pesquisa foi submetida ao Comitê de Ética em Pesquisa - CEP da Universidade São Francisco, através da Plataforma Brasil, com o parecer técnico aprovado sob o número: 3.034.817.

Para o desenvolvimento deste estudo, a empresa escolhida como Lócus de pesquisa foi uma transportadora, situada numa cidade do interior do estado de São Paulo e o corpus recebem nesta pesquisa nomes fictícios. A organização deste artigo é apresentada em referencial teórico, análise de dados e conclusão final.

\section{REFERENCIAL TEÓRICO}

Michel Foucault, filósofo do século XX, contribuiu academicamente por meio de seus estudos e ao estudar sua vida, é possível perceber em suas obras há um discurso silencioso em sua própria constituição. Presenciou guerra, viveu numa família que cultuava a tradição francesa, dedicou-se aos estudos rigorosamente tornando-se um homem solitário. Realizou conferências em diversas universidades pelo mundo. Escrevia artigos para revistas e jornais franceses e foi titular de uma cadeira na instituição francesa Collège de France. Em suas obras produzidas, manifesta os domínios ou fases denominadas como arqueologia, genealogia e ética e, estão presentes a todo o momento histórico.

Segundo Veiga-Neto (2011), estas fases não devem ser entendidas como uma sequência lógica pela qual se finaliza uma e inicia-se outra, mas o que predomina é em que cada obra de Foucault propõe um significado que retrata o domínio.

O foco deste estudo se encontra na segunda fase, ou seja, no domínio da genealogia, que considera a ação de uns sobre os outros, com a proposta de fazer uma descrição da história das muitas interpretações que são contadas e impostas, assim,

[...] a genealogia foi considerar o saber - compreendido como materialidade, prática, acontecimento - peça de um dispositivo político que, como tal, se articula com a estrutura econômica. Ou, mais especificamente, a questão foi a de como se formaram domínios de saber a partir de práticas políticas disciplinares (FOUCAULT, 2015, p.27)

\subsection{Governamentalidade}

Para Foucault (2015), a arte de governar, se apresenta de dois modos, sendo um deles a razão do Estado, através da governamentalidade. É nesse momento que o Estado adquire a importância na genealogia, pois aparece como objeto de estudo para o filósofo.

Foucault (2015) buscou na história como o governo do príncipe se apresentava por meio de tratados como conselho. Estes tratados se apresentavam como a arte de governar. O príncipe recebe o reino por meio de herança, aquisição ou conquista, através de tradição ou violência respectivamente, diante de acordos com outros príncipes. E o governo do príncipe se manifesta com o objetivo de proteger, 
reforçar seu principado, devido a sua fragilidade diante de inimigos. Com isso, se estabelece as relações de força e condução de estratégias para poder identificar a origem do perigo.

Em seus estudos, Foucault (2015) não quis definir conceitos do governo do Estado em sua forma política, mas problematizar o governo através das relações de exterioridade, o exercício do poder, as múltiplas práticas de governo etc.

Porém, para Foucault (2015) a arte de governar está presente em "muitos governos, em relação aos quais o do príncipe governando seu Estado é apenas uma modalidade. Por outro lado, todos esses governos estão dentro do Estado ou da sociedade" (FOUCAULT, 2015, p.411).

Ressalta Foucault (2015) que governar é governar as coisas. Ou seja, governar os homens e as suas relações com as coisas a fim de conduzi-los a um fim específico. Estas coisas se referem às riquezas, os recursos, os meios de subsistência etc., ou seja, estão de forma interligadas entre si e fazem parte da economia. $\mathrm{O}$ autor ainda destaca que, nestas coisas estão os costumes, hábitos, formas de agir e pensar do homem.

A população, sendo sujeito de necessidades e aspirações, se torna objeto do governo, que utiliza de suas táticas para melhorar a sorte da população, aumentar a riqueza, prolongar sua vida, enfim, com isso o governo controla a população sem que esta se dê conta, pois está sob um regime dominado pelas técnicas de governo.

Para Foucault (2015), o conjunto composto por: governo, população e economia, ainda não foram desmembrados a partir do século XVIII e ele define governamentalidade como:

1) o conjunto constituído pelas instituições, procedimentos, análises e reflexões, cálculos e táticas que permitem exercer esta forma bastante específica e complexa de poder, que tem por alvo a população, por forma principal de saber a economia política e por instrumentos técnicos essenciais os dispositivos de segurança. 2) a tendência que em todo o Ocidente conduziu incessantemente, durante muito tempo, à preeminência deste tipo de poder, que se pode chamar de governo, sobre todos os outros - soberania, disciplina, etc. - e levou ao desenvolvimento de uma série de aparelhos específicos de governo e de um conjunto de saberes.3) o resultado do processo através do qual o Estado de justiça da Idade Média, que se tornou nos séculos XV e XVI Estado administrativo, foi pouco a pouco governamentalizado (FOUCAULT, 2015, p. 429).

Estudar a governamentalidade é promover reflexões do papel das empresas no que se refere à educação. Ou seja, o que as mobiliza a desempenharem a dispor da educação junto a seus funcionários, visto que no contexto neoliberal, as empresas têm como principal caráter de gerar riquezas, através de operação mercantil junto à sociedade.

\subsection{A Ordem do Discurso}

Michel Foucault (2014) inicia sua obra "A Ordem do Discurso" se questionando o que deveria proferir naquele momento. Iniciou, que gostaria que as palavras o envolvessem, para que uma voz sem nome o conduzisse o desenrolar, sem a presença daquele de que parte o discurso. 
Nas suas reflexões, questiona qual é o perigo das pessoas falarem e seus discursos serem proclamados sem limite, visto que o filósofo afirma que as instituições afirmam não haver perigo no discurso, pois está na ordem das leis. Porém, ressalta que tanto as instituições quanto o desejo podem estar em oposição no que tange a algumas inquietações do discurso e estas se permearem de forma obscura, trazendo "poderes e perigos que mal se imagina" (FOUCAULT, 2014, p.8) no cotidiano.

Foucault (2014) nos mostra que o discurso efetua uma classificação, divisão de coisas, dos sujeitos dentro de seus contextos de forma organizada, para que possa exercer sua influência de forma silenciosa e assim a sociedade ser conduzida aos seus interesses sem que se aponte sua responsabilidade diante das coisas.

A vontade de verdade, para o autor, permite que o sujeito não enxergue o discurso verdadeiro como prodigiosa maquinaria destinada a excluir todos aqueles que, ponto por ponto, em nossa história, procuram contornar essa vontade de verdade e recolocá-la em questão contra a verdade (FOUCAULT, 2014).

$\mathrm{Na}$ Educação, o autor destaca que o ensino é um sistema ritualizado de palavras, que através dela é possível modificar os discursos encontrados na sociedade dos discursos, "senão uma qualificação e uma fixação dos papéis para os sujeitos doutrinários que falam [...], senão uma distribuição e uma apropriação do discurso com seus poderes e saberes" (FOUCAULT, 2014, p.42).

Diante das discussões promovidas pelo autor na obra Ordem do Discurso, esta pesquisa pretende entender como a Educação Corporativa é parte de uma nova ordem de discurso, pois conforme Foucault (2014, p.7), as instituições nos mostram que o discurso está "na ordem das leis e que o poder advém somente dele".

\subsection{O Neoliberalismo e o Capital Humano}

Para Foucault (2018) a palavra neoliberalismo nasceu de um dos intervencionistas que participava do Colóquio Walter Lippmann, na França, e este termo estabelecia a expressão do liberalismo positivo3 no sentido de intervenção.

Porém antes, é importante discutir sobre liberalismo, a partir de Michel Foucault (2018). Ele destaca que esta nova arte de governar é como uma gestora de liberdade que se instaura no século XVIII e denominada como liberalismo, porque destaca três traços: primeiro: veridicç̧ão do mercado em que "os fisiocratas, bem como para Adam Smith, a liberdade do mercado pode e deve funcionar de tal modo que, através e graças a essa liberdade de mercado, se estabeleça aquilo a que se chama o preço natural ou os bons preços, etc" (FOUCAULT, 2018 p.83). Segundo, a limitação pelo cálculo da utilidade governamental, quando Foucault (2018) remete a política interna do imperador Napoleão, isto é, "as intervenções que fazia no Conselho de Estado e no modo como pensava a sua própria prática governamental"

\footnotetext{
${ }^{3} \mathrm{O}$ liberalismo positivo, expressado pelo autor, significa que não se deve ter a expressão no sentido de posição política que possa remeter a classificação, como no caso, de liberalismo de esquerda. Mas sim, referir-se a esta doutrina como também de liberalismo social ou neoliberalismo.
} 
(FOUCAULT, 2018, p.89) e por terceiro, a posição da Europa como região de desenvolvimento econômico ilimitado relativamente a um mercado mundial.

Para Foucault (2018), o liberalismo ou a arte liberal de governar não é um fenômeno da economia ou política, "mas sim uma espécie de naturalismo governamental que se desempenha em meados do século XVIII" (FOUCAULT, 2018, p.91). Essa naturalidade destacada pelo filósofo é porque ocorrem mecanismos espontâneos na economia e o governo deve conhecer esta natureza para esforçar-se a respeitar. Contudo, o liberalismo do termo 'liberal' é uma prática de governo que consome a liberdade. Assim, o liberalismo, apresenta-se como gestora de liberdade no sentido de produzir ou destruir algo para que possa ser livre.

Para Foucault (2018), a liberdade de comportamento na governamentalidade de um regime liberal deve ser produzida e organizada de forma a servir de regulador e de controle para que os "trabalhadores não tornem um perigo para a empresa ou para a produção” (FOUCAULT, 2018, p.96).

Desta forma, ele aborda que o Estado não tem essência, não é universal e não é uma fonte autônoma de poder em si mesmo. Em suma, o Estado possui um efeito móvel de governamentalidade com um regime de múltiplas faces.

Para Foucault (2018), o neoliberalismo atual se situou a partir da inversão de uma economia sob a vigilância do Estado através de análise do nazismo pelos ordoliberais. Isto significa que o Estado estaria limitado à vigilância do mercado, ou seja,

a liberdade do mercado com o princípio organizador e regulador do Estado, desde o início da sua existência até à última forma das intervenções. Ou seja, um Estado sob a vigilância do mercado e não um mercado sob a vigilância do Estado (FOUCAULT, 2018, p.154).

Assim, a liberdade do mercado pode servir de princípio, de forma e de modelo para o Estado. De acordo com Foucault (2018), os neoliberais definem o estilo de ação governamental através do monopólio (concorrência, preço), ação econômica (controle de inflação, políticas de crédito) e política social. Estes estilos irão conduzir à política de governo através da vigilância e intervenção e o mercado ser um regulador econômico e social na base da sociedade.

A sociedade é regulada pelos mecanismos da concorrência, ao mesmo em que deseja uma sociedade de empresa e não sociedade ao efeito de mercadoria, pois é na sociedade de empresa que se apresenta o homo oeconomicus, como "homem da empresa e da produção" (FOUCAULT, 2018, p. 191). E é na sociedade de empresa que se sustenta o projeto neoliberal.

Contudo, Foucault (2018) expõe uma questão sobre a arte neoliberal de governar, pois quanto mais as empresas se multiplicam mais é necessária uma arbitragem jurídica.

A partir dos anos 80 do século XX, na economia ocidental, iniciava uma nova ordem política com o objetivo de superar a inflação, com a queda dos lucros e desaceleração do crescimento.

Contudo, esta política necessitava de uma mudança mais radical do que simplesmente restaurar o capitalismo. De acordo com Laval (2016, p.190), esta nova política. 
tem como principal característica o fato de alterar radicalmente o modo de exercício do poder governamental, assim como as referências doutrinais no contexto de uma mudança das regras de funcionamento do capitalismo. Revelam uma subordinação a certo tipo de racionalidade política e social articulada à globalização e à financeirização do capitalismo.

Com isso, havia apenas uma única maneira capaz de orientar o comportamento da nova ordem política, ou seja, fazer do Estado o papel de: defender contra inimigos sejam externos e internos; controlar a população e, assim por dizer, as famílias; articular politicamente sobre novos métodos e objetivo de propiciar situações de mercado e formar indivíduos sob a lógica deste mercado.

Desta forma, conforme Laval (2016), sob uma estratégia neoliberal, o Estado consente o livre mercado, ou seja, a economia livre. Assim sendo, a

'estratégia neoliberal': entenda-se o conjunto de discursos, práticas, dispositivos de poder visando à instauração de novas condições políticas, a modificação das regras de funcionamento econômicos e a alteração das relações sociais de modo a impor esses objetivos. (LAVAL, 2016, p.191)

Laval (2016) recorre a Foucault ${ }^{4}$ para poder explicar o surgimento do objetivo desta nova política sob o termo "estratégia sem sujeito" (LAVAL 2016, p.192). Este mesmo autor aborda que nesta literatura de Foucault a moralização da classe operária na década de 1830 fez produzir a burguesia como responsável pela sua instauração e não a classe burguesa, isto significa que a incorporação foi a partir de um sistema ideológico elaborado. Assim, o objetivo da nova ordem política era regular a concorrência, o que deu início a partir de estratégias ideológicas, emergindo de forma despercebida de modo a disseminarse mundialmente.

Para Laval (2016), a grande virada consistiu em transformar a economia interna de um país ao sistema capitalista de modo que as coisas reagissem e se adaptassem artificialmente à crise e que o neoliberalismo emergisse como uma mais nova teoria econômica. Este mesmo autor destaca que a instauração do neoliberalismo ocorreu devido à conexão da tecnologia, do comércio e da produção atendendo a um projeto político.

Silva (2017) destaca que Laval ${ }^{5}$ analisa o processo de mudança ocorrido com as empresas e assim ele denomina

transformação da empresa como modelo de subjetivação tanto do Estado quanto dos indivíduos. Este modo de subjetivação se funda na concorrência - uma vez mais - e resulta em mutações muito significativas para os indivíduos, o Estado e o mesmo para as empresas. (SILVA, 2017, p. 281)

Silva (2017) aponta que a nova ordem (neoliberalista) deu uma nova expressão às empresas. Aliado a novas técnicas de management e governança corporativa, o neoliberalismo fez decidir a variação de investimentos dos acionistas, ora reduzindo ou aumentando os valores investidos, o aumento da concorrência entre as empresas e sua ampliação, no sentido de que a empresa não poderia mais considerar

\footnotetext{
${ }^{4}$ Michel Foucault, “Le jeu de Michel Foucault", em Dits et écrits II (Paris, Gallimard, 2001, p.306-7)

${ }^{5}$ Bibliografia: A nova razão do mundo - ensaio sobre a sociedade neoliberal (2016)
} 
que seu concorrente seria outra empresa que produzia o mesmo produto ou serviço, mas considerar o holl de concorrentes de empresas que produzam produtos ou serviços semelhantes e que estes possam ser substituídos diante do consumo pelos clientes, ou seja, emerge a concorrência indireta de bens e serviços'

Os Estados tornaram-se elementos correspondentes a esta nova ordem de concorrência, permitindo se submeter duramente às novas restrições como a redução dos direitos adquiridos, redução de salários e gastos públicos e esta dinâmica da globalização manifesta de forma ordenada fazendo com que o sujeito conceba em todas as dimensões de sua vida e se comporte como tal. Enfim, a globalização vem instaurar uma nova ordem das atividades econômicas, das relações sociais, dos comportamentos e das subjetividades.

Quanto à questão individual, Silva (2017, p.282) diz "a subjetivação neoliberal assume a forma de empresa de si mesma". Ou seja, o colaborador torna-se uma empresa, desenvolvendo suas capacidades que permitam atingir o seu melhor desempenho nas suas atividades. Silva (2017) complementa

quando bem realizada, esta gestão da alma permite um desempenho ótimo que resulta em um gozo repleto de implicações para a formação subjetiva [...]. Uma consequência fundamental da formação de "neossujeitos" é a destruição de laços pessoais, o que acarreta uma série de efeitos patológicos importantes, como a corrosão da personalidade, a depressão generalizada, a dessimbolização e as várias formas de sofrimento no trabalho. (SILVA, 2017, p. 282)

É importante destacar que Silva (2017) aponta que o neoliberalismo vêm a ser o governo de si, ou seja, segundo Costa (2009), esta se instituindo processos e políticas de subjetivação que têm transformado sujeitos de direitos em indivíduos-microempresas. Isto explica que neste momento contemporâneo as relações sociais e o comportamento dos indivíduos estão sob os efeitos dos processos econômicos da sociedade, restringindo o papel do Estado.

Neste momento de contemporaneidade, a competitividade entre as empresas é cada vez mais acirrada. O tempo, a informação e o conhecimento são elementos importantes para poderem se destacar neste mercado neoliberal. Com efeito, a empresa desenvolve ações junto aos colaboradores para que atendam ao planejamento estratégico da corporação. Estas ações visam promover aos colaboradores competências, aptidões para que possam executar suas atividades de forma autônoma e direta.

A empresa mobilizada, por seus objetivos, proporciona condições para que possa gerar riqueza. Isto significa que a empresa e os colaboradores tornam-se agentes propulsores para esta condição de gerar riqueza. Assim, estes dois agentes irão abranger dois componentes indispensáveis, sendo: o capital humano e o capital intelectual. Conforme López-Ruiz (2007, p.281), "o capital intelectual é um ativo da empresa", complementa ainda, "o capital intelectual de uma empresa são seus ativos indiretos 'conhecimento organizacional, satisfação do cliente, inovação do produto, disposição dos empregados, patentes e marcas registradas"” (LOPÉS-RUIZ, 2007, p.281).

\footnotetext{
${ }^{6}$ Como exemplo: Se uma família possui o hábito de lazer frequentar pizzaria aos finais de semana, significa que existe uma concorrência entre as pizzarias. Porém se a família substituir este lazer do final de semana por um teatro significa que o teatro e pizzaria são concorrentes, mesmo oferecendo produtos distintos.
} 
Ao se entrelaçar estes dois agentes, os colaboradores e a empresa, na busca por resultados, o capital humano se apresenta como a base principal para que o capital intelectual se manifeste através da construção do conhecimento, sejam nos processos, desenvolturas de gerenciamento, tecnologias, informações sobre clientes, mercado etc., conforme Lópes-Ruiz (2007). Ou seja, sem o colaborador, não há possibilidade de suscitar a prosperidade da empresa.

De acordo com López-Ruiz (2007, p. 15), capital humano é "um conjunto de capacidades, destrezas e aptidões próprias dos homens, adquire valores de mercado e se apresenta como forma de capital - entendido como uma soma de valores de troca que serve base de real a uma empresa capitalista".

Costa (2009) destaca que o Estado efetua o investimento de capital no indivíduo e, assim, ele é um elemento de e da produção. Tal que, elemento de produção por ser resultado dos investimentos dos dispositivos de governamentalidade 7 do Estado e enquanto elemento da produção, pois o categoriza como fator do capital de produção.

Para Costa (2009), produzir e acumular capital humano são esforços que a economia passa a concentrar na contemporaneidade. O que significa que não é mais preocupação da economia em relação aos processos ligados à produção. $\mathrm{O}$ autor ainda destaca que existe uma estreita relação da teoria do capital humano com a educação, pois a educação deve funcionar como "investimento cuja acumulação permite não só o aumento da produtividade do indivíduo-trabalhador, mas também a maximização crescente de seus rendimentos ao longo da vida" (COSTA 2009, p. 177), ou seja, um discurso velado do neoliberalismo.

\subsection{Educação Corporativa}

A Educação Corporativa foi introduzida no Brasil, através da Profa. Maria Eboli que realizou seus estudos nos EUA. Para Eboli (2012) a Educação Corporativa desenvolve competências empresariais e humanas fundamentais para a gestão do negócio da empresa.

No Brasil, a partir de 2004, desencadeou um cenário econômico propício para novas posturas corporativas das empresas, através da qualidade de produtos e serviços, performance no atendimento a clientes, atendimento de exigências legais de exportação etc. Isso obrigou aos profissionais das empresas buscar por novos conhecimentos e saberes.

A Educação Corporativa, segundo Eboli (2012), apresenta sete princípios que são elementos principais para o planejamento a implantação e a análise do projeto de Educação Corporativa na empresa, sendo eles: competividade, com o propósito de desenvolver o capital intelectual dos colaboradores para poder elevar a competitividade da organização; perpetuidade, em que a educação deverá ser um processo intencional e sistemático de difusão da cultura na empresa; conectividade, em construção social do conhecimento através da conexão dos públicos interno e externo da organização; disponibilidade, em propiciar os recursos para as atividades educacionais de forma fácil ao acesso; cidadania, estimular o exercício da cidadania individual e corporativo para a construção do conhecimento organizacional, a fim

\footnotetext{
${ }^{7}$ Significa governar de forma corretas as coisas, conduzindo-as para atingir objetivos. Este conceito é discutido no capítulo de Governamentalidade de Michel Foucault.
}

Cadernos Cajuína, V. 6, N. 1, 2021, p. 23-35. 
de que os colaboradores possam refletir a realidade da organização e propor modificações; parceria, desenvolver permanentemente as competências essenciais dos colaboradores; promover parcerias com líderes e gestores para que envolvam a educação de suas equipes e se responsabilizem pela aprendizagem deles; promover parcerias com universidades, instituições de nível superior e até mesmo clientes e fornecedores, que possam agregar valor aos programas educacionais corporativos; e por fim, efetividade, ser um centro de resultados para empresa, o que significa buscar fontes de recursos orçamentários (própria ou autossustentável, para que o sistema educacional seja contínuo, permanente e estratégico).

De acordo com Meinster (1999), para poder superar a concorrência do mercado é necessário que o colaborador adquira competência (a soma de conhecimento, habilidade e atitudes) de forma que lhe proporcione a compreensão de demandas complexas do ambiente corporativa, ou seja, compreender as atividades que consiste dos colegas de trabalho como também, todas as áreas dentro da empresa.

A educação corporativa deve dialogar com a cultura organizacional e fazer parte do cotidiano da organização. Ela vem com propósito de uma solução para desenvolver as pessoas e que sejam capazes de refletir criticamente sobre a realidade da empresa, propondo modificações constantes em favor da competitividade do mercado. O processo de aprendizagem irá oferecer aos colaboradores das empresas treinamentos em várias competências do ambiente de negócios, as quais suportam e ajudam a definir a vantagem competitiva da organização. Ou seja, a educação corporativa irá propiciar novos comportamentos, valores e posturas de seus colaboradores.

\section{ANÁLISE ATRAVÉS DAS VOZES DOS SUJEITOS}

Aqui, é apresentado a análise de excertos, oriundos das entrevistas com colaboradores da empresa pesquisa.

Ao ser questionado, Corin, sobre o motivo pelo qual a empresa oferece programa educacional aos colaboradores, ela responde:

\footnotetext{
capacitar melhor os colaboradores a fim do serviço sair com melhor qualidade. $\mathrm{O}$ colaborador com mais conhecimento tem maior consciência da importância do seu trabalho
}

No primeiro momento, observa-se que a empresa exerce o papel de "dispositivo e que as estratégias de relações de força sustentando tipos de saber e sendo sustentadas por eles" (FOUCAULT, 2015, p.367), o que significa que o interesse da empresa, ao ofertar cursos e treinamentos é guiar, estimular, formar e empoderar seus colaboradores, de modo que produza resultados para que a organização maximize seus resultados.

Esta condução que a empresa proporciona aos colaboradores motivada pelo seu interesse expõe o sujeito "a riscos e assumindo inteira responsabilidade por eventuais fracassos" (LAVAL, 2016, p.328). Dito de outro modo, todo o conhecimento adquirido por ele, irá incorporar seu capital intelectual de modo que produza com qualidade e com perspectivas de satisfações a empresa de resultados não atingidos, pois os recursos foram disponibilizados, neste caso, o conhecimento através de um treinamento, ora, a 
Educação Corporativa. Assim, Corin se coloca como mais consciente da importância de seu trabalho na empresa.

$\mathrm{Na}$ entrevista com Dominique, foi questionado como os cursos oferecidos pela empresa a sensibilizaram:

Eu fiquei contente, uma forma de reconhecimento. Porque a gente pode aprender e colocar isso em prática aqui, aqui dentro mesmo! Então aí...eu fiquei contente, fique.....néh?! A gente fica motivado e fiquei contente com essa ajuda que eu tive.

Nesse excerto, percebe-se a satisfação da Dominique em ter tido a experiência de participar de treinamentos promovidos pela empresa e, o mais cativante na fala dela é sobre a possibilidade de aplicar o conhecimento aprendido na prática. Ou seja, a conduta de suas atitudes, ao desempenhar as tarefas de sua função, a partir deste novo aprendizado, serão diferentes, no sentido de novas condutas, novas formas, outros jeitos. Isto significa, também, que o conhecimento aprendido lhe ofereceu algo novo para seu interior e o encantamento que emerge permite ser "energia" para enfrentar desafios do cotidiano. A lição aprendida através do aprendizado é aplicada na prática e propicia viver experiências com sensações peculiares para cada sujeito. Neste caso, Dominique, a sua experiência de ter participado de treinamentos pela empresa e podido aplicar o conhecimento, lhe proporcionou resultados satisfatórios no desempenho de suas atividades, ou seja, modificou o seu modo de ser. Assim, se mostra sensibilizada pela educação corporativa oferecida pela empresa.

Ao entrevistar Francis, fora questionado sobre se os treinamentos oferecidos pela empresa, desperta entusiasmo para com a equipe de colegas de trabalho. Ele responde,

\footnotetext{
Meus colegas de trabalho também estavam entusiasmados para aprender. Porque a máquina, essa injetora/programadora, por mais que você conheça ela, você tem que estar inteirado sobre ela. Porque durante o dia, acontece situações, que as vezes o mecânico não pode sair de outra máquina pra vir você.
}

É curioso que esse acolhimento para participar do treinamento, tanto por parte de Francis como de seus colegas de trabalho é para que possam desempenhar suas atividades sem ter que depender de uma pessoa habilitada, neste caso, o mecânico, o que é de sua competência executar a manutenção nas máquinas. Ou seja, o conhecimento permite ampliar sua autonomia ao desempenhar suas atividades, caso algum imprevisto aconteça, ele possa promover algum ajuste devido.

Esta autonomia irá gerar em Francis uma independência de ordem técnica por outro profissional, contudo, na interiorização da autonomia desencadeou na fala de Francis a objetivação para novas perspectivas. Francis relata que "deseja retomar meus estudos para poder trabalhar registrado e efetuar alguns bicos por fora". Ou seja, ele entende que o estudo, seja por livre iniciativa ou através de uma empresa com vínculo de trabalho, é uma forma de construir novas possibilidades, de estar à frente das coisas da vida.

Complemento com Foucault que ao falar sobre educação (2014, p.41) diz,

a educação, embora seja, de direito, o instrumento graças ao qual todo indivíduo, em uma sociedade como a nossa, pode ter acesso a qualquer tipo de discurso, é bem sabido 
que segue em distribuição, no que permite e no que impede, as linhas que estão marcadas pela distância, pelas oposições e lutas sociais

Estar envolvido a qualquer tipo de discurso é penetrar nas relações sociais que discursam com suas verdades para a qual incitam o desejo daquilo que se luta e pelo empoderamento.

\section{CONCLUSÃO}

O neoliberalismo possui uma relação de poder com a sociedade através da economia e, mobiliza as empresas pelo desejo de acumular e obter riqueza. Nisso, Educação Corporativa atua no discurso das empresas por meio da qualificação profissional de seus colaboradores, com objetivo de atender sua demanda e objetivos, oriundas deste mercado.

A Educação Corporativa nos seus princípios, conforme Eboli (2012) traz os interesses empresariais em manter-se e ampliar-se no mercado. O conhecimento como forma de potencializar suas metas, pelo qual as pessoas com capacidade de reflexão, transforma a organização além dos preceitos empresariais, ou seja, perpetua a cultura da empresa, os valores e a missão de forma a subjetivar seus colaboradores.

A Educação Corporativa propicia melhor desempenho profissional para os colaboradores que ajustam ao discurso do mercado. Diante disso, manifesta interesse tanto pelo colaborador, pois deseja manter-se empregado, quanto da empresa, que tem como objetivo que seu capital possua cada vez mais valor econômico para o mercado.

O capital humano torna-se importante elemento para o neoliberalismo, pois the proporciona a governamentalidade sobre o sujeito e o faz responsável pelo cuidado de si, ou seja, as suas posses interiores como sua capacidades e habilidades, por meio do capital humano, valorizando-se e transformando num produto vendável. 


\section{REFERÊNCIAS}

COSTA, Sylvio de Sousa Gadelha. Governamentalidade neoliberal, teoria do capital humano e empreendedorismo. 2009. Disponível na revista eletrônica Educação Realidade, no site https://seer.ufrgs.br/educacaoerealidade/article/view/8299. Acessado em 15/08/2019

EBOLI, Marisa. Educação Corporativa: da teoria à prática. Organizado por Fabiana G. Casarini e Marcos Baumgartner. Editora Senac - São Paulo, 2012.

FOUCAULT, Michel. A Ordem do Discurso: aula inaugural no College de France, pronunciada em 2 de dezembro de 1970. Tradução Laura Fraga de Almeida Sampaio - 24 ed. São Paulo: Edições Loyola, 2014

FOUCAULT, Michel. Microfísica do Poder - organização, introdução e revisão técnica Roberto Machado - 2ed. Rio de Janeiro: Paz e Terra, 2015

FOUCAULT. Michel. Nascimento da Biopolítica. (pp. 25 - 208 e pp. 361 - 390) Portugal - Edições 70. Tradução de Pedro Elói Duarte.Biblioteca Nacional de Portugal. Edições 70, 2018

LAVAL, Christian. Dardot, Pierre. A nova razão do Mundo - ensaio sobre a sociedade neolioberal. (pp.187-376). $1^{\circ}$ ed. - São Paulo: Boitempo, 2016

LÓPEZ-RUIZ. Osvaldo. Os executivos das transacionais e o espírito do capitalismo - Capital Humano e empreendedorismo como valores sociais. Rio de Janeiro: Azougue Editorial, 2007

MEISTER, Jeanne C. Educação Corporativa - A gestão do capital Intelectual através das Universidades Corporativas. São Paulo: Pearson Makron Books, 1999

SILVA, Thiago Dias da. Resenha: A nova razão do mundo: ensaio sobre o neoliberalismo - de Pierre Dartot e Christian Laval. Vol. 14, nº. 2, julho-dezembro, 2017, p.278-283

TRIVIÑUS, Augusto N.S. Introdução a pesquisa em ciências sociais: a pesquisa qualitativa em educação. São Paulo. Atlas.1987

VEIGA-NETO, Alfredo. Foucault e Educação. $3^{\circ}$ ed. Belo Horizonte: Autêntica Editora, 2011 